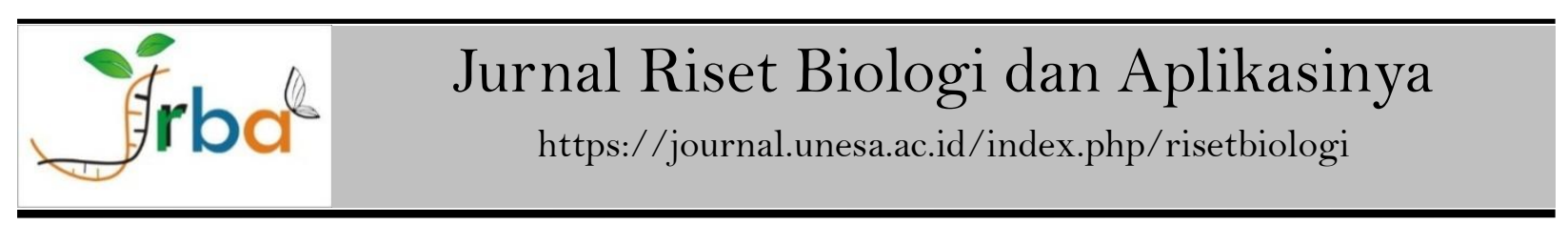

\title{
The Comparison of SARS-CoV-2, SARS-CoV, and MERS-CoV Genome and Spike Protein Variations
}

\author{
Choirun Nita Fikriani ${ }^{1}$, I Kade Karisma Gita Ardana ${ }^{1}$, Dwi Listyorini ${ }^{1,2}{ }^{*}$ \\ ${ }^{1}$ Department of Biology, Faculty of Mathematics and Natural Sciences, Universitas Negeri Malang \\ ${ }^{2}$ Department of Biotechnology, Faculty of Mathematics and Natural Sciences, Universitas Negeri Malang \\ Jln. Semarang 5, Malang, East Java 65145, Indonesia \\ *Corresponding Author: \\ e-mail: listyorini.aljabari@um.ac.id
}

\begin{abstract}
Article History
Received : 20 February 2021

Revised : 14 March 2021

Approved : 22 March 2021

Published : 31 March 2021
\end{abstract}

\section{Keywords}

SARS-CoV-2; MERS-CoV; SARS-CoV; Spike Protein; Corona Virus

Genome;RBM

\begin{abstract}
SARS-CoV-2 is a virus that has caused COVID-19 pandemic. This virus is a new variant of the SARS-CoV virus and also closely related to MERS-CoV, which caused similar acute respiratory infections. All these viruses recognize target cells by binding to the Receptor Binding Domain (RBD) on Spike protein with receptors. This study aimed to determine the SARS-CoV-2, MERS-CoV, and SARS-CoV genome structure, Spike protein sequence differences, and variations of RBD's Receptor Binding Motif (RBM). This research was using data mining approach. Genome sequences were downloaded from NCBI, except for Indonesian samples were downloaded from GISAID. Genomic structures, Spike sequence, and RBD structure were analyzed using Bioedit, followed by protein modelling using SwissModel and PyMol applications. The result showed that the SARS-CoV-2, MERS-CoV, and SARS-CoV genome shared the same genes yet in different numbers and length. SARS-CoV-2 Spike protein sequence was quite similar to SARS-CoV Spike protein, but very different to the Spike protein of MERS-CoV. There were variations of RBD's RBM structure due to the mutations occurred among these viruses. It is suggested that these differences may increase the affinity between SARS-CoV-2 Spike protein to its hACE2 receptor which caused SARSCoV-2 becomes more infective and spread wider than SARS-CoV and MERS-CoV, in turn. This result expected to be basic information for the development of SARSCoV-2 introduction inhibition agent and spreading prevention.
\end{abstract}

How to cite: Fikriani, C.N., Ardana, I.K.K.G., \& Listyorini, D. (202 1). The Comparison of SARS-CoV-2, SARS-CoV, and MERS-CoV Genome and Spike Protein Variations. Jurnal Riset Biologi dan Aplikasinya, 3(1):38-44.

DOI: https://doi.org/10.26740/jrba.v3n1.p38-44.

\section{INTRODUCTION}

SARS-CoV-2 is a virus that has caused COVID-19 pandemic (Sahu et al., 2020). The First case of COVID-19 pandemic was reported in Wuhan, China at the end of December 2019, however cross contamination is estimated to have occurred at the end of November or early December 2019 (Mizumoto \& Chowell, 2020). On March 2, 2020 Indonesia reported two confirmed cases of COVID-19 (Tosepu et al., 2020). SARS-CoV-2, SARS-CoV, and MERS-CoV belong to the same genus, namely Beta-coronavirus but differ in their subgenus (Saha et al., 2020). All of these viruses cause similar infections in the respiratory tract. MERS-CoV has caused Middle East Respiratory
Syndrome (MERS) with the first case in Zarqa, Jordan on 4 April 2012 (Zhu et al., 2020) while SARS-CoV caused an outbreak of Severe Acute Respiratory Syndrome (SARS) in East Asia (Wu et al., 2020) with the first case in Foshan, China on November 16, 2002 (Zhu et al., 2020).

SARS-CoV-2 recognizes target cells by hydrogen bonding some amino acids with the Angiotensin Converting Enzyme 2 (ACE2) protein (Wan et al., 2020). Protein viral that are responsible for introducing to host cells are known as Spike protein especially in the Receptor Binding Domain (RBD) (Xia et al., 2020). The bond between RBD and ACE2 protein is mediated by several major amino acids or Receptor Binding Motif (RBM) 
(Watanabe et al., 2020). SARS-CoV and MERS$\mathrm{CoV}$ also recognize target cells by binding RBD to receptors (Hoffmann et al., 2020). MERS-CoV uses dipeptidyl peptidase (DPP4) as the main receptor (Zhou et al., 2020) while SARS-CoV uses ACE2 protein as one of the receptor (Devaux et al., 2020). The binding of viral proteins to host cells is very important in the search for an agent to prevent infection. A comparative understanding of SARSCoV-2, SARS-CoV, and MERS-CoV genome structure, Spike protein sequence differences, Receptor Binding Motif of Receptor Binding Domain variations revealed in this research were expected to provide an overview of the molecular background which leads to the development of currently unpredicted spreading behavior. Furthermore, it also expected that this result would be able to become a source of scientific basic information in the development of candidates for the prevention of virus introduction into host cells and treatment of COVID-19.

\section{MATERIALS AND METHODS}

The samples in this study were genomic structures and Spike protein sequences from SARSCoV-2, MERS-CoV, and SARS-CoV viruses, which were obtained through data mining process from NCBI (https://www.ncbi.nlm.nih.gov) and GISAID (https://www.gisaid.org/) available from March 2020 to June 2020.

This research was initiated by downloading genome sequences of SARS-CoV-2, MERS-CoV, and SARS-CoV viruses from NCBI, then analyzing the structure of its structure. To find out the differences of Spike protein sequences, the entire sequence of Spike gene was downloaded in Fasta (.fas) format from NCBI, except of samples from Indonesia were obtained from GISAID. Open Reading Frame $(O R F)$ was identified using NCBI ORF-Finder. To determine its differences, Spike protein sequences from all samples were aligned using Bioedit. Multiple alignments of RBD fragments were carried out to identify the RBM differences among those three viruses. Protein modelling was carried out using a modeling application in the SwissModel (https://swissmodel.expasy.org) to determine the possible changes occurred.

In order to further analysis of the differences in its protein structures due to the mutation found, the superimposition alignment process was carried out using PyMOL application. The conserved domain was marked and the conformation variations were marked in different color.

\section{RESULT AND DISCUSSION}

\section{The Comparison of SARS-CoV-2, SARS-CoV, and MERS-CoV Genome}

SARS-CoV-2, SARS-CoV, and MERS-CoV genome consisted of 11,13 , and 10 structural and functional genes, which spans for $29.9 \mathrm{kbp}, 29.8$ $\mathrm{kbp}$, and $30.1 \mathrm{kbp}$ in length, respectively. Each gene encodes structural proteins or functional ones. Structural genes including Membrane (M), Envelope $(E)$, Nucleocapsid $(N)$, and Spike $(S)$, while functional ones consist of several ORFs which encodes various proteins including some polymerase enzymes for genome replications (ORFIa and ORFIab) and accessories proteins (ORF3s up to ORF1O). Looking more carefully on the number and type of genes bears by each virus, we found that all three are bearing some different ORF genes. ORF1a and ORF 1ab found in SARS-CoV-2, SARS-CoV, and MERS-CoV, while ORF6, ORF 7a, and ORF $7 b$ are shared only by SARS but not MERS corona viruses. ORF3, ORF4a, ORF4 $b$, and ORF5 are exclusively found in MERS but not SARS corona virus, while ORF3b, ORF8a, ORF9a, and ORF9b are exclusively found in SARS-CoV, while ORF3a, ORF8, and ORF1O are exclusively found in SARS-CoV-2 (Figure 1). Considering its length and total number of genes, it unveiled that SARS-CoV-2 \& SARS$\mathrm{CoV}$ bear additional gene/s with smaller size compared to MERS-CoV. It is suggested that genes length do not significantly affect its function.

SARS-CoV-2, SARS-CoV, and MERS-CoV share the same structural genes in different length. $S, M, N, E$ genes respectively spend 3822 bp, 669 bp, 1260 bp, 228 bp length in SARS-CoV-2; 4068 bp, 660 bp, 1243 bp, 249 bp in MERS-CoV; and 3768 bp, 666 bp, 1269 bp, 231 bp in SARS-CoV. A slight difference in its length seems also not to affect the proteins encoded. All three demonstrate a full normal physical structure with intact functions. Furthermore, focusing on Spike protein which plays important role on host recognition, we suggest that 246 bp deletion (82 amino acid shorter) compared to SARS-CoV Spike protein may affect significantly on its protein structure and its function in turn, since protein structure is important in virus shape and morphogenesis (Xu et al., 2020). Some mutations in SARS-CoV-2 Spike gene have been suggested to be the culprit of this virus different spreading behavior (Hartenian et al., 2020). It is supported with the fact 
that spreading rate of SARS-CoV-2 is higher than SARS-CoV and MERS-CoV (Zhu et al., 2020). SARS-CoV spread across 220 countries, SARS-CoV only spread in 4 countries, and MERS-CoV spread in 27 countries (WHO, 2020). Indonesian National Health Ministry (2020) reported that SARS-CoV-2 was spread across all provinces in Indonesia.

\section{Variation of Spike Protein Sequence}

In this study we collected 12 samples available from Asian, European, and American countries representatives during the data mining time-line of this research. As much as 4 Spike RNA sequences of SARS-CoV-2, MERS-CoV, and SARS-CoV were downloaded. The accession numbers and protein identity numbers were recorded as of its availability in order to trace back once it was required (Table 1).

The differences of SARS-CoV-2, MERS-CoV, and SARS-CoV Spike protein sequences from each country were identified using multiple alignments which revealed that from 12 samples there were only 2 amino acid differences in SARS-CoV-2 (Table 2), while SARS-CoV and MERS-CoV bear 4 (Table 3) and 5 (Table 4) differences, respectively. From this finding and the fact of the wider area of SARS-CoV-2 spreading compared to SARS-CoV and MERS-CoV, it suggested that the number of mutations could not be a sole reason for its ability to spread, and other factors should be considered, including its receptor in the target cells or organisms. There was no available data on both SARS-CoV and MERS-CoV from Indonesia. However, learning from the collected samples,
China variant of SARS-CoV bears more mutation than those of other 3 samples. Meanwhile it is more random mutation in MERS-CoV regarding the area (Table 3 and 4). Yet, since the available data until the end of the research due was very limited, it is not possible to claim any clear conclusion on the mutation rate or its tendency. A phylogenetic approach and additional data are required to understand better for this case. Multiple alignment of all samples indicated that Spike protein of SARSCoV-2 has a high similarity to the SARS-CoV while both SARS-CoV-2 and SARS-CoV showing a significant difference to MERS-CoV. SARS-CoV-2 Spike protein of Indonesian samples bear two different amino acid compared to China (Wuhan), France, and USA (Table 2), while SARS- CoV Spike protein is known to have 4 different amino acids (Table 3) and MERS-CoV are 5 different amino acids (Table 4).

Sequence differences by means of any types of mutation or as a natural variation may change the amino acid sequences, which in turn gives rise to a functional divergence of its encoded protein (Hulswit et al., 2016), virulence (Sicari et al., 2020) and pathogenesis of the virus (Mousavizadeh \& Ghasemi, 2020; Abdullahi et al., 2020). Spike protein of corona viruses plays role as an intermediary for the introduction of the virus with its receptors on the host cell (Xia et al., 2020); it facilitates the fusion of the host cell as the first step of infection (Chakraborty \& Bhattacharjya, 2020). During the infection process, conformation is induced when the virus enters the endosome of the host cell (Bai \& Warshel, 2020).

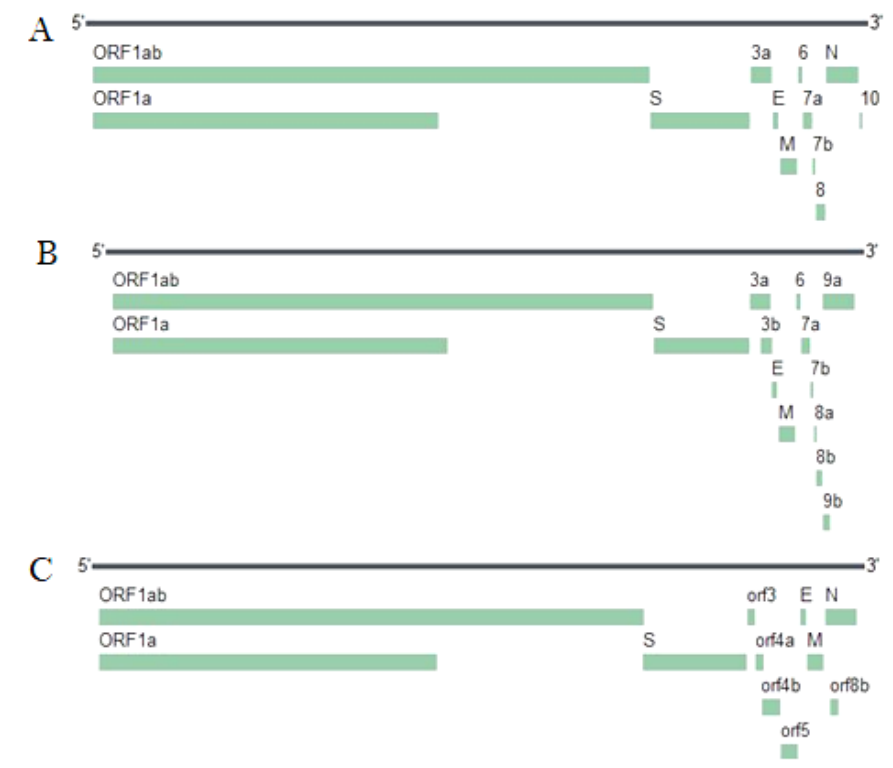

Figure 1. Genome Structure A. SARS-CoV-2, B. SARS-CoV, and C. MERS-CoV 
Table 1. The Data Origin of Spike (S) Gene Sequences

\begin{tabular}{ccllcc}
\hline No. & Virus & Data Origin & Sample Origin & $\begin{array}{c}\text { Accession } \\
\text { Number }\end{array}$ & Protein id \\
\hline 1 & SARS-CoV-2 & NCBI & Wuhan, China & NC_045512.2 & YP_009724390.1 \\
2 & SARS-CoV-2 & GISAID & Jakarta, Indonesia & EPI-ISL-437192 & FJ882945.1 \\
3 & SARS-CoV-2 & NCBI & USA & ACZ72035.1 \\
4 & SARS-CoV-2 & NCBI & France & MT470142.1 & QJT72590.1 \\
\hline 5 & MERS-CoV & NCBI & Seoul, South Korea & KX034100.1 & ANC28711.1 \\
6 & MERS-CoV & NCBI & Thailand & KT225476.2 & ALO51904.1 \\
7 & MERS-CoV & NCBI & Florida, USA & KJ829365.1 & AHZ64549.1 \\
8 & MERS-CoV & NCBI & France & & \\
\hline 9 & SARS-CoV & NCBI & Beijing, China & AY864805.1 & AAY60780.1 \\
10 & SARS-CoV & NCBI & Hong Kong & GU553363.1 & ADC35483.1 \\
11 & SARS-CoV & NCBI & Tennessee, USA & FJ882945.1 & ACZ72035.1 \\
12 & SARS-CoV & NCBI & Italy & AY323977.2 & AAP72986.1 \\
\hline
\end{tabular}

Table 2. SARS-CoV-2 Spike (S) Protein Mutations

\begin{tabular}{llcc}
\hline \multirow{2}{*}{ No. } & \multicolumn{1}{c}{ Country } & \multicolumn{2}{c}{ Amino Acid Position } \\
\cline { 3 - 4 } & & $\mathrm{572}$ & $\mathbf{8 2 2}$ \\
\hline 1. & Wuhan, China & $\mathrm{T}$ & $\mathrm{L}$ \\
2. & France & $\mathrm{I}$ & $\mathrm{L}$ \\
3. & Jakarta, Indonesia & $\mathrm{T}$ & $\mathrm{F}$ \\
4. & USA & $\mathrm{L}$ \\
\hline
\end{tabular}

Table 3. SARS-CoV Spike (S) Protein Mutations

\begin{tabular}{cccccc}
\hline \multirow{2}{*}{ No. } & \multirow{2}{*}{ Country } & \multicolumn{4}{c}{ Amino Acid Position } \\
\cline { 3 - 5 } & & $\mathbf{7 7}$ & $\mathbf{2 4 4}$ & $\mathbf{4 3 6}$ & $\mathbf{8 6 3}$ \\
\hline 1. & Beijing, China & $\mathrm{D}$ & $\mathrm{T}$ & $\mathrm{Y}$ & $\mathrm{T}$ \\
2. & Hongkong & $\mathrm{G}$ & $\mathrm{I}$ & $\mathrm{Y}$ & $\mathrm{I}$ \\
3. & Tennessee, USA & $\mathrm{G}$ & $\mathrm{I}$ & $\mathrm{H}$ & $\mathrm{T}$ \\
4. & Italy & $\mathrm{G}$ & $\mathrm{I}$ & $\mathrm{Y}$ & $\mathrm{T}$ \\
\hline
\end{tabular}

Table 4 MERS-CoV Spike (S) Protein Mutations

\begin{tabular}{|c|c|c|c|c|c|c|}
\hline \multirow{2}{*}{ No. } & \multirow{2}{*}{ Country } & \multicolumn{5}{|c|}{ Amino Acid Position } \\
\hline & & 683 & 829 & 833 & 914 & 1193 \\
\hline 1. & Seoul, South Korea & $\mathrm{S}$ & $\mathrm{S}$ & Q & Q & $\mathrm{A}$ \\
\hline 2. & Thailand & $\mathrm{S}$ & $\mathrm{A}$ & $\widetilde{Q}$ & $\widetilde{Q}$ & A \\
\hline 3. & Tennessee, USA & $\mathrm{F}$ & $\mathrm{S}$ & $\widetilde{\mathrm{R}}$ & $\widetilde{Q}$ & A \\
\hline 4. & France & $\mathrm{S}$ & $\mathrm{S}$ & Q & $\widetilde{\mathrm{H}}$ & $\mathrm{S}$ \\
\hline \multicolumn{7}{|c|}{$\begin{array}{l}\text { Note: } \mathrm{L}=\text { Leusine, } \mathrm{F}=\text { Phenylalanine, } \mathrm{D}=\text { Aspartic acid, } \mathrm{G}=\text { Glycine, } \mathrm{T}=\text { Threonine, } \mathrm{I}= \\
\text { Isoleucine, } \mathrm{Y}=\text { Tyrosine, } \mathrm{H}=\text { Histidine, } \mathrm{S}=\text { Serine, } \mathrm{A}=\text { Alanine, } \mathrm{Q}= \\
\text { Glutamine, and } \mathrm{R}=\text { Arginine. }\end{array}$} \\
\hline \multicolumn{7}{|c|}{ Table 5. Receptor Binding Motif Variations } \\
\hline No. & SARS-CoV-2 & & -CoV & \multicolumn{3}{|c|}{ MERS-CoV } \\
\hline 1. & Asparagine (N439) & & ne $(\mathrm{R})$ & \multicolumn{3}{|c|}{ Proline $(\mathrm{P})$} \\
\hline 2. & Leucine (L455) & & ne $(Y)$ & \multicolumn{3}{|c|}{ Asparagine $(\mathrm{N})$} \\
\hline 3. & Phenylalanine (F486) & & he $(\mathrm{L})$ & \multicolumn{3}{|c|}{ Serine $(\mathrm{S})$} \\
\hline 4. & Glutamine (Q493) & & ine $(\mathrm{N})$ & \multicolumn{3}{|c|}{ Glutamic Acid (E) } \\
\hline 5. & Glutamine ( $\left.\widetilde{Q}_{498}\right)$ & & ne $(\mathrm{Y})$ & \multicolumn{3}{|c|}{ Leucine $(\mathrm{L})$} \\
\hline 6. & Asparagine (N501) & & ine $(T)$ & \multicolumn{3}{|c|}{ Serine $(\mathrm{S})$} \\
\hline
\end{tabular}

The high similarity of Spike protein sequence unveiled in this research may lead to the understanding of the introduction behavior of both SARS-CoV-2 and SARS-CoV which both bind to
ACE2 as the main receptor (Wan et al., 2020). It may also clarify the difference among SARS-CoV-2 and SARS-CoV in one side and MERS-CoV in other side which binds to dipeptidyl peptidase-4 (DPP4) as its main receptor (Zhou et al., 2020). 
We also unveiled the variations in the Receptor Binding Motif, especially in its Receptor Binding Domain (RBD). RBD in Spike protein has an important role in determining affinity of the viral binding to introduce into the host cell (De Wit et al., 2016). Receptor Binding Motif in RBD SARSCoV-2 facilitates the binding to hACE2 (Walls et al., 2020). This variation already been reported to increase the affinity level of SARS-CoV-2 Spike protein to hACE2 which to be higher than its counterpart in SARS-CoV (Shang et al., 2020). Based on that fact it has been believed to be the reason why SARS-CoV-2 has become more infective than SARS-CoV (Awasthi \& Sarkar, 2020). That behaviour suggested to be the result of amino acid residues differences (Table 5; Figure 2);
Phenylalanine (F486) in SARS-CoV-2 interacts with M82, L79, and Y83 residues of ACE2 while Leucine in SARS-CoV interacts with M82 and L79 residues of ACE2 residues (Gussow et al., 2020). Meanwhile Glutamine (Q493) in SARS-CoV-2 exhibits a good Van der Waals value resulting to the higher affinity than Asparagine in SARS-CoV (Figure 3). Taken together, those revealed variations suggested to be the cause of higher spread rate of SARS-CoV-2 compared to SARS-CoV and MERS-CoV (Zhu et al., 2020). Further analysis on the binding affinity between Spike protein and its receptors is being done currently. We expect to get better understanding on this virus behavior and find clue in controlling its spreading.

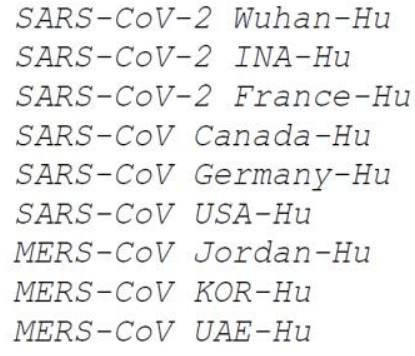

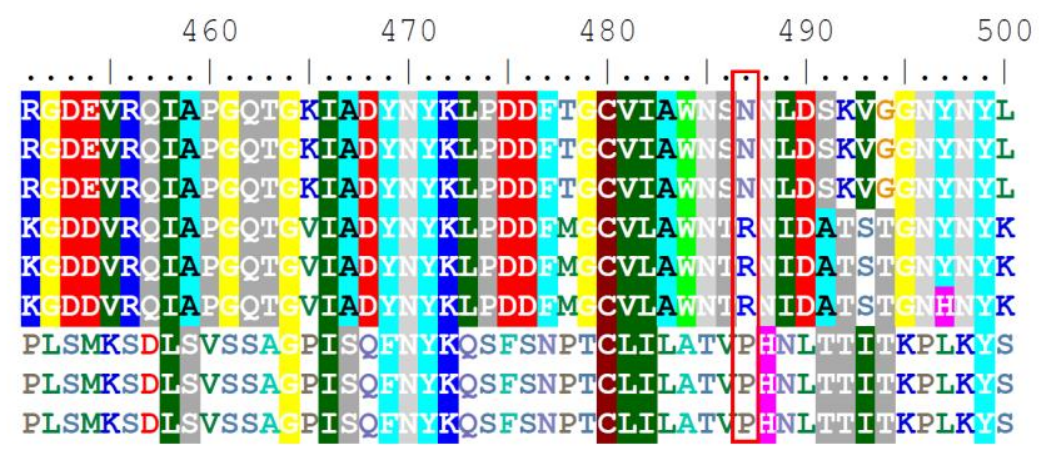
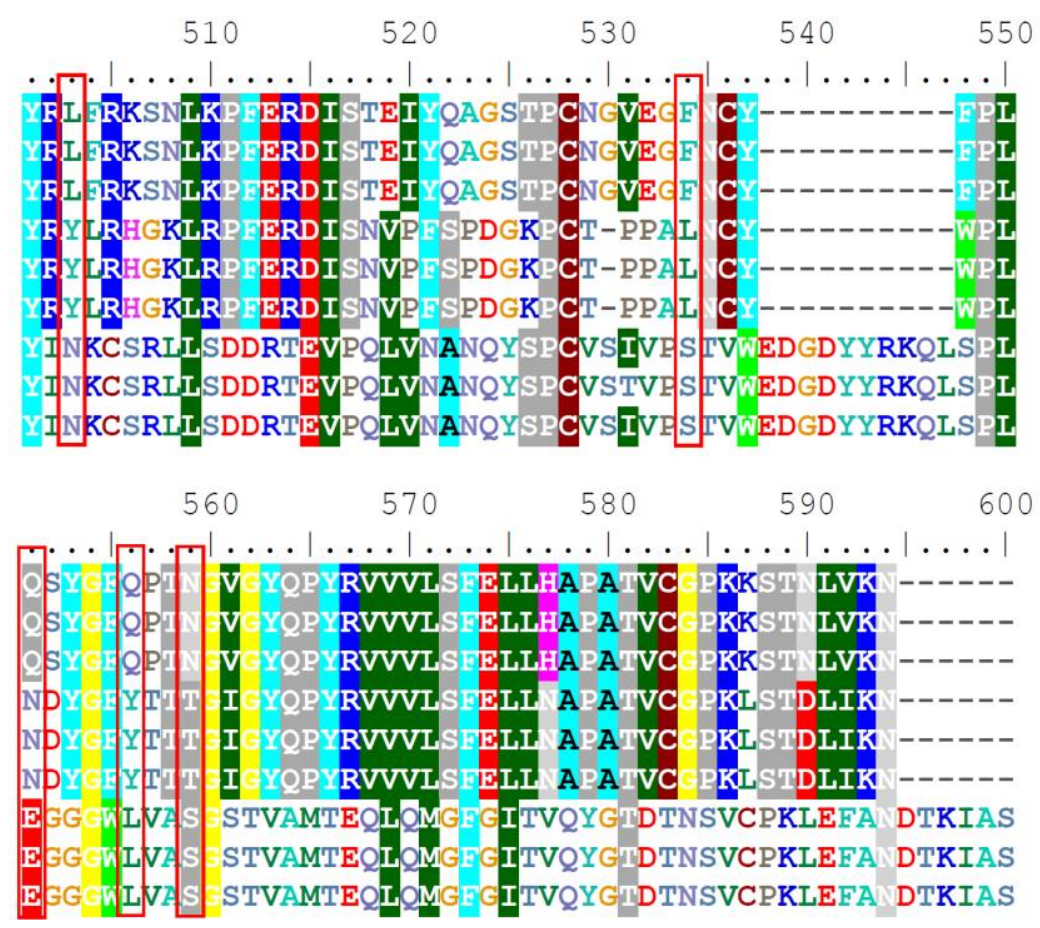

Figure 2. The Difference of Receptor Binding Motif between SARS-CoV-2, SARS-CoV, and MERS-CoV 


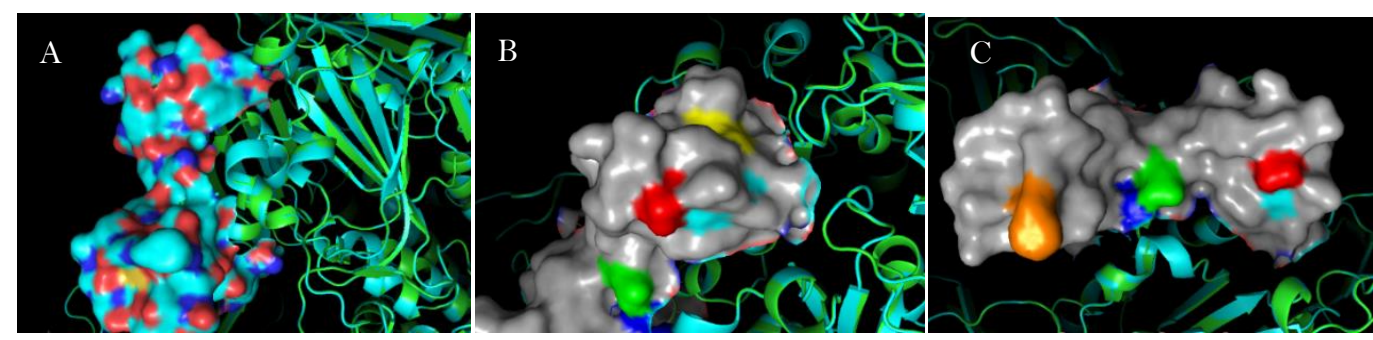

Figure 3. A. Receptor Binding Domain on Spike Protein, B \& C Receptor Binding Motif on Receptor Binding Domain area (Yellow=Asparagine-Arginine, Dark Blue=Leucine-Tyrosine, Orange $=$ Phenylalanine-Leusine, Green $=$ Glutamine-Asparagine, Red=Glutamine- Tyrosine, and Blue=Asparagine-Threonine)
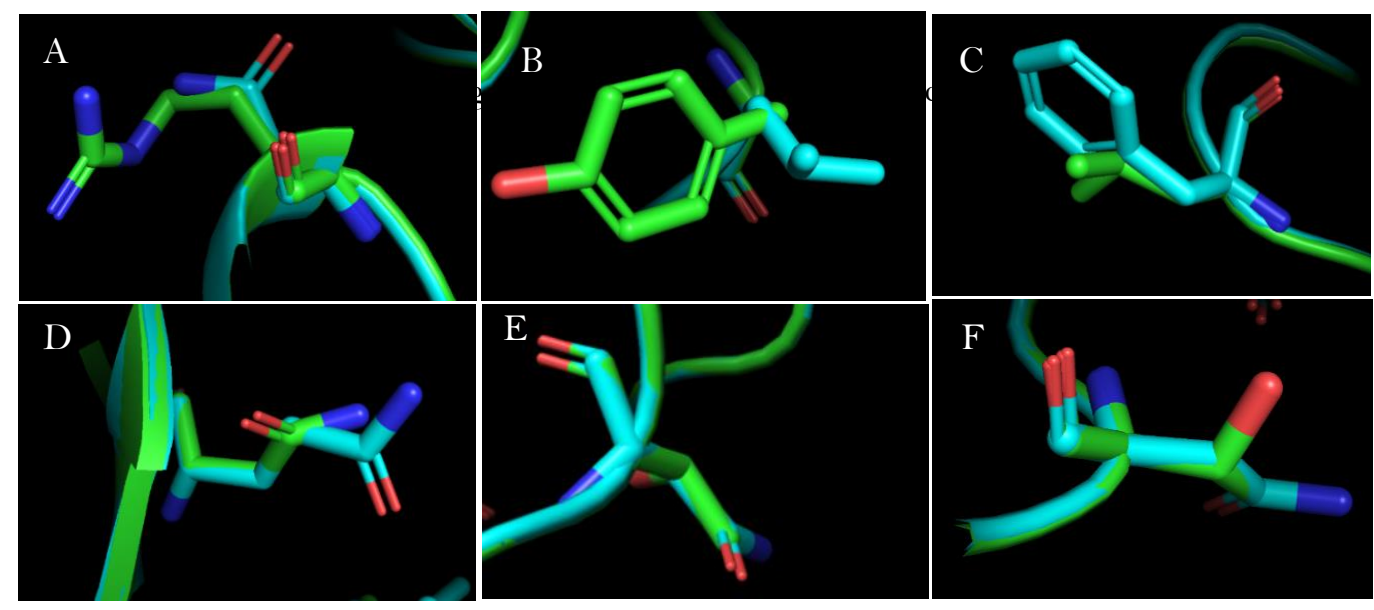

Figure 4 Receptor Binding Motif: Blue $=$ SARS-CoV-2 and Green $=$ SARS-CoV

A. Asparagine-Arginine, B. Leusin-Tyrosine, C. Phenylalanine-Leusine

D. Glutamine-Asparagine, E. Glutamine- Tyrosine, and F. Asparagine-Threonine

\section{CONCLUSION}

This study revealed that SARS-CoV-2, MERS-CoV, and SARS-CoV genome has the same types of genes with different length, numbers, and sequences. The Spike protein sequence of SARSCoV-2 was quite similar to the Spike protein of SARS-CoV, yet very different from the Spike protein of MERS-CoV. Among SARS-CoV-2, MERS-CoV, and SARS-CoV we also revealed the RBM variations of Spike's RBD. We conclude that those variations may cause the different behavior in its introduction process, which leads to the wider spreading of SARS-CoV-2. Current study is working to unveil the binding behavior of this virus.

\section{ACKNOWLEDGEMENTS}

The authors would like to express our gratitude to LP2M Universitas Negeri Malang. This research was funded by Hibah Skripsi scheme of PNBP UM year 2020 to D.L. and C.N.F.

\section{REFERENCES}

Abdullahi, I. N., Emeribe, A. U., Ajayi, O. A., Oderinde, B. S., Amadu, D. O., \& Osuji, A. I. (2020). Implications of SARS-CoV-2 genetic diversity and mutations on pathogenicity of the COVID-19 and biomedical interventions. Journal of Taibah University Medical Sciences, $\quad 15(4), \quad 258-264$. https://doi.org/10.1016/j.jtumed.2020.06.005

Awasthi, M., \& Sarkar, D. P. (2020). N-terminal domain ( NTD) of SARS-CoV-2 spike- protein structurally resembles MERS-CoV NTD sialoside-binding pocket. $1-11$.

Bai, C., \& Warshel, A. (2020). Critical Differences between the Binding Features of the Spike Proteins of SARSCoV-2 and SARS-CoV. Journal of Physical Chemistry B, 124(28), 5907-5912. https://doi.org/10.1021/acs.jpcb.0c04317

Chakraborty, H., \& Bhattacharjya, S. (2020). Mechanistic insights of host cell fusion of SARS-CoV-1 and SARS-CoV-2 from atomic resolution structure and membrane dynamics. Biophysical Chemistry, 265(June), 106438. https://doi.org/10.1016/j.bpc.2020.106438

De Wit, E., Van Doremalen, N., Falzarano, D., \& Munster, V. J. (2016). SARS and MERS: Recent insights into emerging coronaviruses. Nature Reviews Microbiology, 14(8), 523-534. https://doi.org/10.1038/nrmicro.2016.81

Devaux, C. A., Rolain, J. M., \& Raoult, D. (2020). ACE2 receptor polymorphism: Susceptibility to SARS- 
CoV-2, hypertension, multi-organ failure, and COVID-19 disease outcome. Journal of Microbiology, Immunology and Infection, 53(3), 425-435. https://doi.org/10.1016/j.jmii.2020.04.015

Gussow, A. B., Auslander, N., Faure, G., Wolf, Y. I., Zhang, F., \& Koonin, E. V. (2020). Genomic determinants of pathogenicity in SARS-CoV-2 and other human coronaviruses. Proceedings of the National Academy of Sciences of the United States of America, 117(26), 15193-15199. https://doi.org/10.1073/pnas.2008176117

Hartenian, E., Nandakumar, D., Lari, A., Ly, M., Tucker, J. M., \& Glaunsinger, B. A. (2020). The molecular virology of coronaviruses. Journal of Biological Chemistry, 295(37), 12910-12934. https://doi.org/10.1074/jbc.REV120.013930

Hoffmann, M., Kleine-Weber, H., Schroeder, S., Krüger, N., Herrler, T., Erichsen, S., Schiergens, T. S., Herrler, G., Wu, N. H., Nitsche, A., Müller, M. A., Drosten, C., \& Pöhlmann, S. (2020). SARS-CoV-2 Cell Entry Depends on ACE2 and TMPRSS2 and Is Blocked by a Clinically Proven Protease Inhibitor. Cell, 181(2), 271-280.e8. https://doi.org/10.1016/j.cell.2020.02.052

Hulswit, R. J. G., de Haan, C. A. M., \& Bosch, B. J. (2016). Coronavirus Spike Protein and Tropism Changes. In Advances in Virus Research (1st ed., Vol. 96). Elsevier https://doi.org/10.1016/bs.aivir.2016.08.004

Mizumoto, K., \& Chowell, G. (2020). Estimating the risk of 2019 Novel Coronavirus death during the course of the outbreak in China, 2020. MedRxiv, 191-192. https://doi.org/10.1515/9780822396086-023

Mousavizadeh, L., \& Ghasemi, S. (2020). Genotype and phenotype of COVID-19: Their roles in pathogenesis. Journal of Microbiology, Immunology and Infection, $\quad x \times x x, \quad 0-4$. https://doi.org/10.1016/j.jmii.2020.03.022

Saha, O., Shatadru, R. N., Rakhi, N. N., Islam, I., \& Rahaman, M. (2020). possible implications from the ongoing outbreak in Bangladesh.

Sahu, K. K., Mishra, A. K., \& Lal, A. (2020). Comprehensive update on current outbreak of novel coronavirus infection (2019-nCoV). Annals of Translational Medicine, 8(6), 393-393. https://doi.org/10.2 1037/atm.2020.02.92

Shang, J., Ye, G., Shi, K., Wan, Y., Luo, C., Aihara, H., Geng, Q., Auerbach, A., \& Li, F. (2020). Structural basis of receptor recognition by SARS-CoV-2. Nature, $\quad$ 581(7807), 221-224. https://doi.org/10.1038/s41586-020-2 179-y

Sicari, D., Chatziioannou, A., Koutsandreas, T., Sitia, R., \& Chevet, E. (2020). Role of the early secretory pathway in SARS-CoV-2 infection. Journal of Cell Biology, 219(9), 1-13. https://doi.org/10.1083/JCB.20200600508132020 $\mathrm{C}$

Tosepu, R., Gunawan, J., Effendy, D. S., Ahmad, L. O. A. I., Lestari, H., Bahar, H., \& Asfian, P. (2020).
Correlation between weather and Covid-19 pandemic in Jakarta, Indonesia. Science of the Total Environment, 725. https://doi.org/10.1016/j.scitotenv.2020.138436

Walls, A. C., Park, Y. J., Tortorici, M. A., Wall, A., McGuire, A. T., \& Veesler, D. (2020). Structure, function and antigenicity of the SARS-CoV-2 spike glycoprotein. BioRxiv, January. https://doi.org/10.1101/2020.02.19.956581

Wan, Y., Shang, J., Graham, R., Baric, R. S., \& Li, F. (2020). Receptor Recognition by the Novel Coronavirus from Wuhan: an Analysis Based on Decade-Long Structural Studies of SARS Coronavirus. Journal of Virology, 94(7), 1-9. https://doi.org/10.1128/jvi.00127-20

Watanabe, Y., Allen, J. D., Wrapp, D., McLellan, J. S., \& Crispin, M. (2020). Site-specific glycan analysis of the SARS-CoV-2 spike. Science, 369(6501), 330-333. https://doi.org/10.1126/science.abb9983

Wu, Y., Ho, W., Huang, Y., Jin, D. Y., Li, S., Liu, S. L., Liu, X., Qiu, J., Sang, Y., Wang, Q., Yuen, K. Y., \& Zheng, Z. M. (2020). SARS-CoV-2 is an appropriate name for the new coronavirus. The Lancet, $395(10228)$, 949-950. https://doi.org/10.1016/So 140-6736(20)30557-2

Xia, S., Liu, M., Wang, C., Xu, W., Lan, Q., Feng, S., Qi, F., Bao, L., Du, L., Liu, S., Qin, C., Sun, F., Shi, Z., Zhu, Y., Jiang, S., \& Lu, L. (2020). Inhibition of SARS-CoV-2 (previously 2019-nCoV) infection by a highly potent pan-coronavirus fusion inhibitor targeting its spike protein that harbors a high capacity to mediate membrane fusion. Cell Research, 30(4), 343-355. https://doi.org/10.1038/s41422020-0305-X

Xu, R., Shi, M., Li, J., Song, P., \& Li, N. (2020). Construction of SARS-CoV-2 Virus-Like Particles by Mammalian Expression System. Frontiers in Bioengineering and Biotechnology, 8(July), 1-6. https://doi.org/10.3389/fbioe.2020.00862

Zhou, P., Yang, X. Lou, Wang, X. G., Hu, B., Zhang, L., Zhang, W., Si, H. R., Zhu, Y., Li, B., Huang, C. L., Chen, H. D., Chen, J., Luo, Y., Guo, H., Jiang, R. Di, Liu, M. Q., Chen, Y., Shen, X. R., Wang, X., ... Shi, Z. L. (2020). A pneumonia outbreak associated with a new coronavirus of probable bat origin. Nature, 579(7798), 270-273. https://doi.org/10.1038/s41586-020-2012-7

Zhu, Z., Lian, X., Su, X., Wu, W., Marraro, G. A., \& Zeng, Y. (2020). From SARS and MERS to COVID-19: A brief summary and comparison of severe acute respiratory infections caused by three highly pathogenic human coronaviruses. Respiratory Research, 21(1), 1-14. https://doi.org/10.1186/s12931-020-0 1479-w. 